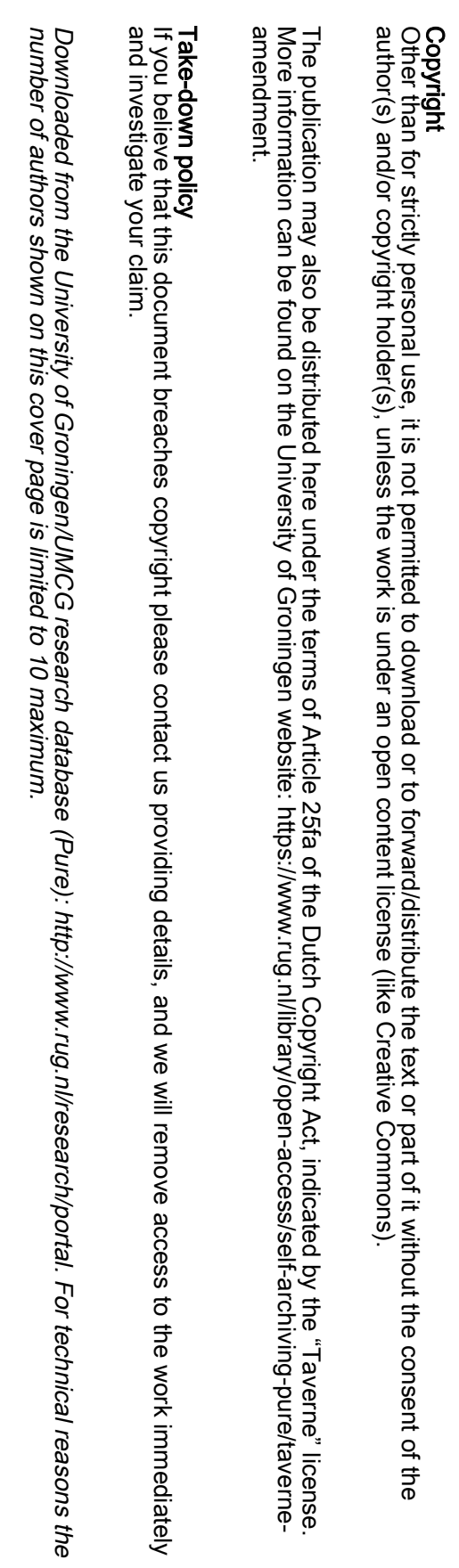

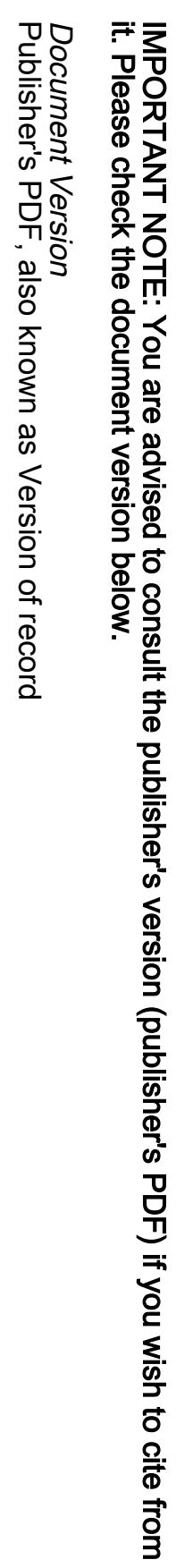

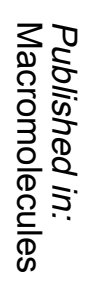

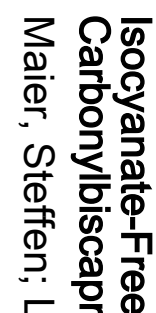

5 응

를 总을

零

ไิ

울 똥

is

공

응 응 욱

ब

( Ф)

미요숭

응응

옹으

는: 응흥

క $ᄋ$

ํㅡㄹ

둥

우 옹우

끙

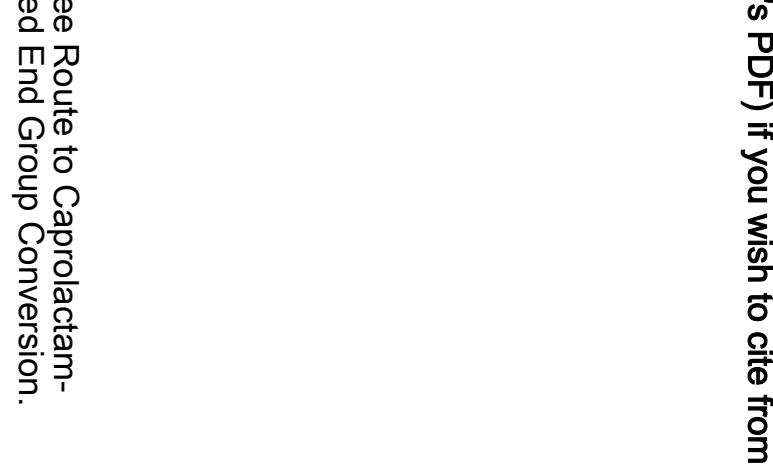
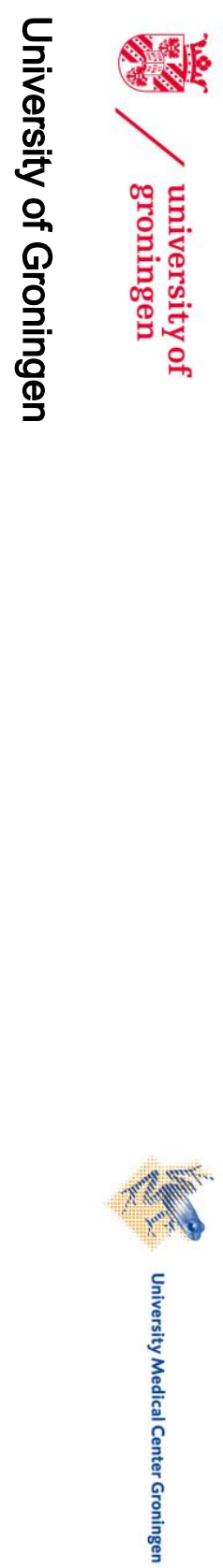


\title{
Isocyanate-Free Route to Caprolactam-Blocked Oigomeric Isocyanates via Carbonylbiscaprolactam- (CBC-) Mediated End Group Conversion
}

\author{
Steffen Maier, ${ }^{\dagger}$ Ton Loontjens, ${ }^{\ddagger, \S}$ Boudewijn Scholtens, ${ }^{\perp, \|}$ and Rolf Miilhaupt ${ }^{*, \dagger, \#}$ \\ Institut für Makromolekulare Chemie und Freiburger Materialforschungszentrum der \\ Albert-Ludwigs-Universität Freiburg, Stefan-Meier-Strasse 21, D-79104Freiburg, Germany, \\ DSMResearch, PObox 18,6160MD Geleen, The Netherlands, and \\ DSM Venturing \& Business Development, PObox 18,6160MD Geleen, The Netherlands
}

Received November 28, 2002, Revised Manuscript Received April 25, 2003

\begin{abstract}
Blocked isocyanate functional oligomers and liquid rubbers are prepared by a novel, solventfree carbonylbiscaprolactam $(\mathrm{CBC})$ mediated end group conversion reaction of amine-terminated oligodimethylsiloxanes (PDMS) and oligopropyleneoxides (PPO), with molar masses varying between 400 and $3140 \mathrm{~g}$ mol, and of hydroxy-terminated oligoethylene oxide (PEG), oligopropyleneoxide (PPO) and oligotetrahydrofuran (PTHF), with molar masses of around $1000 \mathrm{~g}$ mol. The key reaction is the carbonylbiscaprolactam (CBC) mediated amino or hydroxy end group conversion yielding carbamoyl caprolactam functional polymers, without requiring addition of either phosgene or isocyanates. The quantitative $\mathrm{CBC}$ conversion of amine end groups occurred in bulk at $100^{\circ} \mathrm{C}$ in the absence of catalysts, yielding $N$-carbamoyl caprolactam terminated oligomers and caprolactam (ring elimination, pathway RE). The reaction of hydroxy end groups at 100 to $150{ }^{\circ} \mathrm{C}$ in the presence of catalysts such as zirconium alcoholates, magnesium bromide or dibutyltindilaurate (DBTDL) produced $N$-carbamoyl caprolactam end groups via nucleophilic attack of the hydroxy group at one of the CBC caprolactam rings and subsequent ring opening (ring opening, pathway $\mathrm{RO}$ ). The $\mathrm{CBC}$ reactions were monitored by means of ReactIR, $\mathrm{H}$ $N M R$ and ${ }^{13} \mathrm{C} N M \mathbb{R}$ spectroscopy. The molecular masses of the oligomers and liquid rubbers with caprolactam-blocked isocyanate end groups were measured by means of MALDI-ToF mass spectroscopy and size exclusion chromatography (SEC). The thermal behavior and deblocking temperatures of the caprolactam-blocked isocyanates obtained were examined by means of thermogravimetric analysis (TGA).
\end{abstract}

\section{Introduction}

The property profiles of polyurethanes are tailored to meet the diversified demands of various industries. Traditional intermediates are di- and polyfunctional isocyanate resins, most of which are obtained via the phosgene-mediated conversion of the corresponding amines, or via the isocyanate-mediated conversion of the corresponding hydroxy-functional intermediates, respectively. Special safety and processing precautions are required for such reactions because phosgene and low molecular weight isocyanates are very toxic and very sensitive to the presence of water. Mbreover, isocyanatemediated oligomer formation via the conversion of polyols requires addition of a large excess of diisocyanates in order to prevent undesirable molar mass buildup via chain extension or premature gelation, especially in the case of multifunctional branched polyols and polyamines. The excess diisocyanate is either left in the resins or must be removed by vacuum stripping.

To circumvent problems related to the presence of free isocyanates, isocyanates are blocked by reacting them with various blocking groups. Deblocking can be induced thermally or by reacting blocked isocyanates with polyols. Comprehensive reviews on the chemistries and applications of blocked isocyanates were published by Wicks. ${ }^{1,2}$ Today, the applications of blocked isocyanates range from automotive coatings to adhesives, sealants,

\footnotetext{
† Institut für Makromolekulare Chemie und Freiburger Materialforschungszentrum der Albert-Ludwigs-Universität Freiburg.

${ }^{\ddagger}$ DSM Research.

\$E-mail: ton.loontjens@dsm.com.

${ }^{\perp}$ DSM Venturing \& Business Development.

"E-mail: boudewijn.scholtens@dsm.com.

\#E-mail: rolf.muelhaupt@makro.uni-freiburg.de.
}

paper and textile treatment, foams, rubbers, and reinforced plastics. Typical blocking reagents are bisulfites, which produce water-soluble blocked isocyanates, phenols, pyridinols, thiophenols, mercaptopyridines, mercaptans, oximes such as methyl ethyl ketoxime, amides, cyclic amides such as caprolactam, imidazoles, amidines, pyrazoles, 1,24triazoles, and secondary amines. Another simple method of blocking an isocyanate represents the reversible formation of uretdiones by dimerization of isocyanates in the presence of trialkylphosphine catalysts.

Control on polymer structures and safety requirements are an important objective in polyurethane research and development. This makes it necessary to explore isocyanate- and phosgene-free routes to blocked isocyanates via end group conversion of amine and hydroxy end groups. Here we report the use of carbonylbiscaprolactam as a new very versatile, nontoxic reagent that can convert terminal as well as pendant hydroxy-and amine-groups of functional polymers into the corresponding caprolactam-blocked isocyanates without requiring the use of isocyanates.

\section{Experimental Section}

Materials. Carbonylbiscaprolactam (CBC, ALLINCO) was supplied by DSM and used as received (purity $>99 \%$ ). The prepolymers polytetrahydrofuran (PTHF, $M_{n}=1010 \mathrm{~g}$ mol, bis (hydroxy) terminated, DuPont), poly (ethylene glycol) (PEG, $M_{\mathrm{h}}=910 \mathrm{~g}$ mol, bis(hydroxy) terminated, Merck), poly(propylene oxide) (PPO, $M_{n}=990 \mathrm{~g}$ thol, bis (hydroxy) terminated, Aldrich), Jeffamines (M-600. $M_{\mathrm{h}}=590 \mathrm{~g}$ mol, mono(amine) terminated, D-400. $M_{h}=430 \mathrm{~g}$ thol, bis (amine) terminated, D-2000 $M_{h}=1950 \mathrm{~g}$ mol, bis (amine) terminated, all from Fluka and Aldrich), and poly (dimethylsiloxane) (PDMS, $M_{h}=3140 \mathrm{~g}$ tnol, bis (3aminopropyl) terminated, 
Table 1. Uncatalyzed Reactions of CBC with Isopropylenamine Terminated Oligopropyleneoxides (Jeffamines with $\mathbf{M}=$ Mono- and $\mathrm{D}=$ Difunctional) and with $\operatorname{Bis}(N$-propyleneamine) Terminated Poly(dimethylsiloxane) (PDMS) ${ }^{a}$

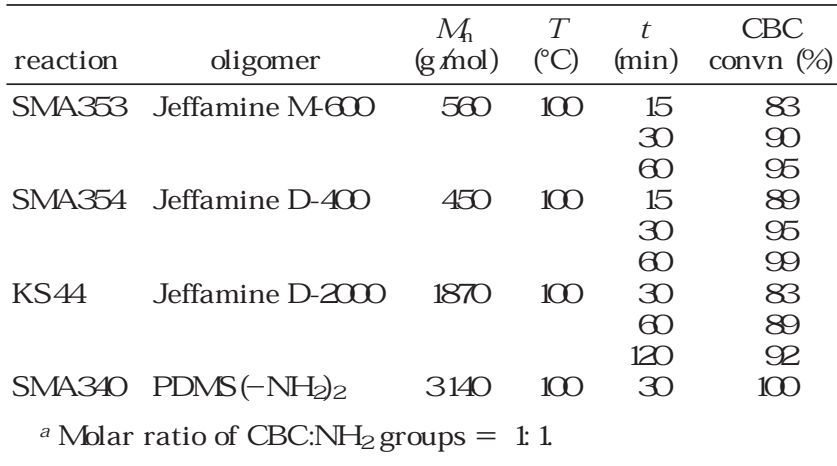

Aldrich) were dried before use. The catalysts $\mathrm{MgBr}_{2}$ from Aldrich and dibutyltin dilaurate (DBTDL) from Fluka were used without further purification. $\mathrm{Zr}\left(\mathrm{O}-\mathrm{n}-\mathrm{C}_{3} \mathrm{H}_{7}\right)_{4}$ was available as $7 \mathrm{Owt} \%$ solution in $n$-propanol from Aldrich. Toluene p.a. (Merck) and $\mathrm{CaCl}_{2}$ (Grüssing) were also used as received.

End Group Conversions with CBC. Amine-terminated oligomers such as mono-, di-, and tri-isopropyleneamineterminated oligopropyleneoxides (Jeffamine) and bis (n-propylene-amine) terminated poly (dimethylsiloxane) (PDMS) were reacted in bulk with $\mathrm{CBC}$ at $100^{\circ} \mathrm{C}$ without catalyst.

Reaction of CBC with Jeffamines. The Jeffamines were dried by stirring for $16 \mathrm{~h}$ at $60^{\circ} \mathrm{C}$ in oil pump vacuum. For example, $10.08 \mathrm{~g}(40 \mathrm{mmol})$ of $\mathrm{CBC}$ was reacted with $224 \mathrm{~g}$ (40mmol) of Jeffamine M-600 ( $M_{h}=560 \mathrm{~g}$ tmol $)$. CBC and the Jeffamine were mixed together and then stirred under argon for the duration of $1 \mathrm{~h}$ at $100^{\circ} \mathrm{C}$. To remove the caprolactam formed, the product mixture was dissolved in $40 \mathrm{~mL}$ of toluene and extracted three times with $30 \mathrm{~mL}$ of an aqueous solution of $\mathrm{CaCl}_{2}(4 \mathrm{Og} \mathrm{L})$. After drying $\left(4 \mathrm{~d}, 50^{\circ} \mathrm{C}\right.$, oil pump vacuum), $2389 \mathrm{~g}(85 \%)$ of a slightly yellow liquid was obtained. Properties are listed in Table 1.

Reaction of CBC with Diamine-Terminated Oligodimethylsiloxane (PDMS). A mixture of $184 \mathrm{~g}(7.32 \mathrm{mmol})$ of $\mathrm{CBC}$ and $115 \mathrm{~g}(366 \mathrm{mmol})$ of PDMS $\left(M_{\mathrm{h}}=3140 \mathrm{~g}\right.$ mol $)$ was stirred under argon for $30 \mathrm{~min}$ at $100{ }^{\circ} \mathrm{C}$. At certain time intervals, samples were removed from the reaction. The caprolactam formed was removed by extracting three times with an aqueous solution of $\mathrm{CaCl}_{2}(40 \mathrm{~g} \mathrm{~L})$. After drying (60 ${ }^{\circ} \mathrm{C}, 2 \mathrm{~d}$, oil pump vacuum) $9.66 \mathrm{~g}$ (77\%) of a slightly yellow liquid was obtained. Reaction conditions and polymer properties are listed in Table 1.

Dihydroxy-terminated oligomers such as PTHF, PEG, and PPO with molecular masses of around $1000 \mathrm{~g}$ inol were reacted in bulk with $\mathrm{CBC}$ at 100 and $150^{\circ} \mathrm{C}$ in the absence and the presence of the catalysts $\mathrm{Zr}(\mathrm{OR})_{4}, \mathrm{MgBr}_{2}$ and DBTDL. The reactions were carried out under argon on a $50 \mathrm{~g}$ scale. The resulting oligomers were dried by stirring for $1 \mathrm{~h}$ at 100 ${ }^{\circ} \mathrm{C}$ at oil pump vacuum. In a typical experiment, the $\mathrm{Zr}-$ alcoholate-catalyzed reaction of $\mathrm{CBC}$ with PTHF is described below.

Reaction of $\mathrm{CBC}$ with $\mathrm{PTHF}$ in the Presence of a $\mathrm{Zr}$-Alcoholate Catalyst. First, $16.75 \mathrm{~g}(665 \mathrm{mmol})$ of CBC, $33.25 \mathrm{~g}(329 \mathrm{mmol})$ of PTHF and $0.224 \mathrm{~mL}(\mathrm{O} .234 \mathrm{~g})$ of a 70 wt \% solution of $\mathrm{Zr}\left(\mathrm{O}-\mathrm{C}_{3} \mathrm{H}_{7}\right)_{4}$ in $n$-propanol (i.e., $\mathrm{O} .5 \mathrm{mmol}$ of $\mathrm{Zr}\left(\mathrm{O}-\mathrm{C}_{3} \mathrm{H}_{7}\right)_{4}, \mathrm{O} .75 \mathrm{~mol} \%$ with respect to $\left.\mathrm{CBC}\right)$ were employed. The $\mathrm{Zr}$ - propylate solution was added to $5 \mathrm{~g}$ of the PTHF, and then the $n$-propanol was removed by stirring for $30 \mathrm{~min}$ at 80 ${ }^{\circ} \mathrm{C}$ in oil pump vacuum. The $\mathrm{CBC}$ was dissolved in the remaining $\mathrm{PTHF}$ and was heated to the reaction temperature. Subsequently the PTHF-catalyst-mixture was added via a syringe. The reaction was stirred for a given time at the reaction temperature and stopped by cooling to room temperature. The reaction was monitored with a ReactIR, and the products were analyzed by ${ }^{1} \mathrm{H}$ and ${ }^{13} \mathrm{C} N \mathrm{NM}$ spectroscopy. Reaction conditions and properties are listed in Tables 2 and 3
Characterization. The reaction products were identified, and the $\mathrm{CBC}$ and end group conversions were determined by means of ${ }^{1} \mathrm{H}$ and ${ }^{13} \mathrm{C} N M \mathbb{R}$ spectroscopy (Bruker ARX300, 300 and $75 \mathrm{MH}$, respectively) and with ReactIR spectroscopy (Mettler, Applied Systems, ReactIR 1000). The molecular masses were measured with SEC (Knauers Mikrogelset $\mathrm{A}_{22} \mathrm{CHCl}_{3}$ $30{ }^{\circ} \mathrm{C}$, with UVRI and low angle laser light scattering detectors, calibration vs PS standards) and MALDI-ToF mass spectrometry (Bruker REFLEX 2 reflex mode, dithranol matrix, $\mathrm{LiBr}$ and $\mathrm{KCl}$ as cationizing agent). The thermal behavior of the caprolactam-blocked oligomers was measured with TGA (Netzsch STA 409).

\section{Results and Discussion}

The carbonylbiscaprolactam (CBC) represents an activated derivative of carbonic acid. It is a nontoxic $\left(\mathrm{LD}_{50}>2000 \mathrm{mg} \mathrm{kg}\right.$ ) white crystalline product that melts at $118^{\circ} \mathrm{C}$. The CBC is readily obtained by reacting phosgene with caprolactam. This route to $\mathrm{CBC}$ was pioneered in 1956 by Meyer, who used CBC together with hexamethylenediamine to produce low molecular weight ureas and amides with rather ill-defined structures. ${ }^{3}$ In 1962 Fawcett et al. reported that $C B C$ was obtained as a byproduct when they studied the reaction of caprolactam with $\mathrm{COF}_{2}{ }^{4}$ In 1967 , the synthesis of $\mathrm{CBC}$ as an intermediate for the synthesis of lysine was disclosed in a Japanese patent. ${ }^{5}$ As difunctional $N$ acyllactam, CBC was used successfully as activator for the anionic ring-opening polymerization of various lactams. ${ }^{6-10}$ In 1996, BASF claimed the use of a large variety of heterocyclic substances, among them CBC, as activators for organic peroxides in washing and bleaching agents. ${ }^{11}$ Since 2000 , DSM and others have filed patents concerning the preparation of CBCand its use as coupling agent, chain extender, or cross-linker. ${ }^{2-19}$

As illustrated in Scheme 1, there exist two very different reaction pathways for $\mathrm{CBC}$ reaction with nucleophiles: first, the ring elimination (pathway $\mathrm{RE}$ ) associated with caprolactam formation, and second, ring opening (pathway $\mathrm{RO}$ ), which does not produce caprolactam as side-product. The reaction pathway $\mathrm{RE}$ is typical for the reaction of phosgene and many other phosgene derivatives such as carbonyldiimidazole. According to pathway $\mathrm{RE}$ the reaction of $\mathrm{CBC}$ with amines $\left(\mathrm{R}-\mathrm{XH}\right.$ in Scheme 1 is $\left.\mathrm{R}-\mathrm{NH}_{2}\right)$ affords formation of either $N$-carbamoyl caprolactam and caprolactam or ureas, accompanied by elimination of both caprolactam molecules. In contrast, CBC also offers the opportunity of nucleophilic attack at the carbonyl group of the caprolactam ring followed by ring opening (pathway $\mathrm{RO})$. In pathway ROno caprolactam is eliminated. Onefold ring opening converts hydroxy groups into esterfunctional $N$-carbamoyl caprolactams. Two-fold ring opening yields polyesterureas. The reaction pathway $\mathrm{RO}$ represents a very special feature of CBC chemistry and is very attractive with respect to reduced emission of low volatile organic compounds such as caprolactam. The predominance of reaction pathway ROwith respect to pathway $\mathrm{RE}$ depends primarily upon the choice of the nucleophile and is also affected by catalyst addition and reaction conditions. Both reaction pathways are very attractive with respect to the end group conversion of hydroxy-and amine-terminated oligomers and the in situ formation of reactive oligomers containing caprolactam-blocked isocyanate end groups without requiring the addition of either phosgene or isocyanates during end group conversion. The end group conversion of amine- and hydroxy-terminated oligomers was investi- 
Table 2 Functionalization Reactions of PTHF $\left(M_{n}=1010 \mathrm{~g} / \mathrm{mol}\right)$, PEG $\left(M_{n}=910 \mathrm{~g}\right.$ mol $)$ and PPO $\left(M_{n}=990 \mathrm{~g}\right.$ mol $)$ with $\mathrm{CBC}$ (Molar Ratio of $-\mathrm{OH}: \mathrm{CBC}=1: 1)^{a}$

\begin{tabular}{|c|c|c|c|c|c|c|c|c|c|c|c|c|}
\hline \multirow[b]{2}{*}{ reaction } & \multirow[b]{2}{*}{ oligomer } & \multirow[b]{2}{*}{ catalyst } & \multirow[b]{2}{*}{$\begin{array}{c}\text { [catalyst] } \\
\text { (mol \%) }\end{array}$} & \multirow[b]{2}{*}{$\begin{array}{c}\text { [catalyst] } \\
\text { (wt \%) }\end{array}$} & \multirow[b]{2}{*}{$\begin{array}{c}T \\
\left({ }^{\circ} \mathrm{C}\right)\end{array}$} & \multirow[b]{2}{*}{$\begin{array}{c}t \\
(\min )\end{array}$} & \multicolumn{5}{|c|}{$\%$ of CBC converted into } & \multirow[b]{2}{*}{$\begin{array}{c}\mathrm{OH} \\
\text { convn (\%) }\end{array}$} \\
\hline & & & & & & & $\begin{array}{c}1 x \\
\mathrm{RO}^{b}\end{array}$ & $\begin{array}{c}1 x \\
\mathrm{RE}^{b}\end{array}$ & urethane & $\begin{array}{c}2 x \\
\mathrm{RE}^{b}\end{array}$ & $\sum$ & \\
\hline SMA224 & \multirow[t]{7}{*}{ PTHF } & none & $\mathrm{O}$ & $\mathrm{O}$ & 200 & 75 & $\mathrm{O}$ & 33 & 13 & 17 & 63 & 93 \\
\hline SMA223 & & $\mathrm{Zr}(\mathrm{OR})_{4}$ & 0.75 & 0.33 & 100 & 120 & 82 & $\mathrm{O}$ & $\mathrm{O}$ & 6 & 88 & 94 \\
\hline SMA225 & & $\mathrm{Zr}(\mathrm{OR})_{4}$ & 0.75 & 0.33 & 150 & 20 & 85 & $\mathrm{O}$ & $\mathrm{O}$ & 6 & 91 & 97 \\
\hline SMA236 & & $\mathrm{MgBr}_{2}$ & 0.75 & O. 18 & 100 & 120 & $\mathrm{O}$ & $\mathrm{O}$ & $\mathrm{O}$ & $\mathrm{O}$ & $\mathrm{O}$ & $\mathrm{O}$ \\
\hline SMA238 & & $\mathrm{MgBr}_{2}$ & 0.75 & O. 18 & 150 & 70 & 65 & 15 & 4 & 6 & 90 & 100 \\
\hline SMA231 & & DBTDL & 0.5 & 0.42 & 100 & 170 & 8 & $\mathrm{O}$ & $\mathrm{O}$ & 4 & 12 & 16 \\
\hline SMA231 & & DBTDL & 0.5 & $0 . \overline{42}$ & 150 & 50 & 18 & $\mathrm{O}$ & 11 & 7 & 36 & 54 \\
\hline SMA315 & \multirow[t]{3}{*}{ PEG } & $\mathrm{Zr}(\mathrm{OR})_{4}$ & 0.75 & 0.33 & 100 & 120 & 75 & $\mathrm{O}$ & 5 & 7 & 87 & 90 \\
\hline SMA316 & & $\mathrm{Zr}(\mathrm{OR})_{4}$ & 0.75 & 0.33 & 150 & 20 & 85 & $\mathrm{O}$ & 10 & 3 & 98 & 100 \\
\hline SMA32Z & & $\mathrm{MgBr}_{2}$ & 0.75 & Q. 18 & 150 & 7 & 79 & 4 & 9 & 4 & 96 & 99 \\
\hline SMA323 & \multirow[t]{3}{*}{$\mathrm{PPO}$} & $\mathrm{Zr}(\mathrm{OR})_{4}$ & 0.75 & 0.33 & 150 & 20 & 86 & $\mathrm{O}$ & 7 & $\mathrm{O}$ & 93 & 99 \\
\hline \multirow[t]{2}{*}{ SMA324 } & & $\mathrm{MgBr}_{2}$ & 0.75 & O. 18 & 150 & 20 & 23 & $\mathrm{O}$ & 11 & $\mathrm{O}$ & 34 & 45 \\
\hline & & & & & & $7 \mathrm{O}$ & 36 & $\mathrm{O}$ & 32 & $\mathrm{O}$ & 68 & 99 \\
\hline
\end{tabular}

${ }^{a}$ No urea was found under the reaction conditions applied. ${ }^{b} \mathrm{RO}=$ ring opening; $\mathrm{RE}=$ ring elimination.

Table 3. Molar Mass Distribution of PTHF and Its CBC Reaction Products, As Determined by Means of Size Exclusion Chromatography (SEC)

\begin{tabular}{llccccc}
\hline sample & catalyst & $\begin{array}{c}T \\
\left({ }^{\circ} \mathrm{C}\right)\end{array}$ & $\begin{array}{c}t \\
(\mathrm{~min})\end{array}$ & $\begin{array}{c}M_{n} \\
(\mathrm{~g} \text { mol })\end{array}$ & $\begin{array}{c}M_{\mathrm{v}} \\
(\mathrm{g} \text { mol })\end{array}$ & $M_{\mathrm{v}} M_{n}$ \\
\hline PTHF & & & & 1670 & 3290 & $2 \mathrm{O}$ \\
SMA223 & $\operatorname{Zr}(\mathrm{OR})_{4}$ & 100 & 120 & 3470 & 5700 & 16 \\
SMA225 & $\operatorname{Zr}(\mathrm{OR})_{4}$ & 150 & 20 & 3000 & 5190 & 1.7 \\
SMA238 & $\mathrm{MgBr}_{2}$ & 150 & 70 & 4630 & 7845 & 1.7 \\
SMA231 & $\mathrm{DBTDL}$ & 150 & 50 & 2130 & 3400 & 1.6
\end{tabular}

gated using spectroscopic methods including ReactIR spectroscopy.

Reactions of $\mathrm{CBC}$ with Amine-Terminated Oligomers. Amine-terminated oligomers such as the bis(n-propylene-amine)-terminated oligodimethylsiloxane (PDMS) and the mono-, di- and tri- isopropylene-amineterminated oligopropyleneoxide (also known under the trade name of Jeffamine) were reacted with CBC in bulk at $100^{\circ} \mathrm{C}$. Reaction conditions and properties are listed in Table 1 According to the spectroscopic studies the reaction of $\mathrm{CBC}$ with amine groups proceeds in the absence of catalyst exclusively via the ring elimination mechanisms shown as pathway RE in Scheme 1. The $N$-carbamoyl caprolactam end groups are equivalent to the corresponding reaction products of the isocyanate with caprolactam. The byproduct caprolactam can be removed by means of vacuum stripping, thin film evaporation or extraction using an aqueous $4 \mathrm{wt} \%$ calcium chloride solution. Interestingly, as evidenced by the absence of urea groups, the N-carbamoyl caprolactam is obtained in almost quantitative yield without any indication of elimination of the second caprolactam ring. Thus, although during the synthesis blocked isocyanates and amines are present simultaneously, no sign of the consecutive reaction forming ureas was noted, meaning that the reaction is very selective. This reaction does not require excess $\mathrm{CBC}$ and is a very clean stoichiometric end group conversion. The end group conversion of the isopropylene-amine-terminated oligopropyleneoxides (Jeffamines) is displayed in Scheme 2

The $\mathrm{CBC}$ conversions of amine end groups were monitored by ReactIR spectroscopy and by ${ }^{1} \mathrm{H}$ and ${ }^{13} \mathrm{C}$ NMR spectroscopy. Figure 1shows the ReactIR spectra of the uncatalyzed bulk reaction of $\mathrm{CBC}$ with Jeffamine $\mathrm{M}-600$ at $100^{\circ} \mathrm{C}$. The $\mathrm{CBC}$ conversion was calculated from the area of the amide II band at $1520 \mathrm{~cm}^{-1}$. The calibration of this method was carried out by correlating the band area at the end of the reaction with the final $\mathrm{CBC}$ conversion, as measured by means of ${ }^{1} \mathrm{H} N M R$ spectroscopy. It can be seen in Figure 2that the reaction rate of $C B C$ with amines is quite high. The $H \mathrm{H} M \mathbb{R}$ spectra of caprolactam blocked isocyanate functionalized Jeffamine and PDMS are shown in Figures 3and 4 . The conversions were calculated from the integrals of the HNMR-signals of the caprolactam blocked isocyanate (393, 262ppm), caprolactam (3 11, 239ppm) and CBC $(38,245 \mathrm{ppm})$.

The CBC conversion with time depends on the nulceophilicity of the amine and the amine concentration. As is apparent from Table 1 and Figures 1 and 2 the amine conversion is very high and quantitative at appropriate reaction times. For the diamine Jeffamine D-400, the conversion amounted 99\%after $1 \mathrm{~h}$, whereas for M-600, 95\% was reached after $1 \mathrm{~h}$. The reaction with Jeffamine D-2000yielded only 89\% after $1 \mathrm{~h}$ and 92\% after $2 \mathrm{~h}$. This is in accord when taking into account the different concentrations of the amine end groups, which is $4.44 \mathrm{mmol} g$ for D-400, $1.79 \mathrm{mmol} g$ for $\mathrm{M}-600$, and only $1.07 \mathrm{mmol} g$ for D-2000. In comparison to the $\mathrm{CBC}$ reactions of the Jeffamines, the reaction of $\mathrm{CBC}$ with diamine-terminated oligodimethylsiloxane (PDMS) was considerably faster and gave quantitative conversion in less than $1 \mathrm{~h}$, although the PDMS amine concentration was only $0.64 \mathrm{mmol}$ \&. Most likely, this remarkable difference in reactivity is closely associated with the nucleophilicity of the amine end groups. The isopropylene-amine end groups of the Jeffamines are sterically more hindered and less nucleophilic with respect to the $n$-propylene-amine end groups of PDMS. Higher steric hindrance requires either higher temperatures or longer reaction times, respectively, to achieve quantitative conversion of the end groups. The ReactIR analysis of Jeffamine reactions performed at different temperatures allowed the determination of the activation enthalpy of the $\mathrm{CBC}$ amine end group conversion which was found to be $55.2 \mathrm{~kJ}$ mol.

Reactions of CBC with Polyols. To examine the possibility of forming $N$-carbamoyl caprolactam from hydroxy-terminated oligomers via the ring opening mechanism (pathway ROin Scheme 1), the reactions of $\alpha, \omega$-dihydroxy-terminated polyols such as oligoethylene oxide (PEG), oligopropylene oxide (PPO), and oligotetrahdyrofuran (PTHF) were investigated. The reaction with $\mathrm{CBC}$ was performed in bulk at 100,150 , 
Scheme 1. Reactions of Carbonylbiscaprolactam (CBC) with Nucleophiles ${ }^{a}$

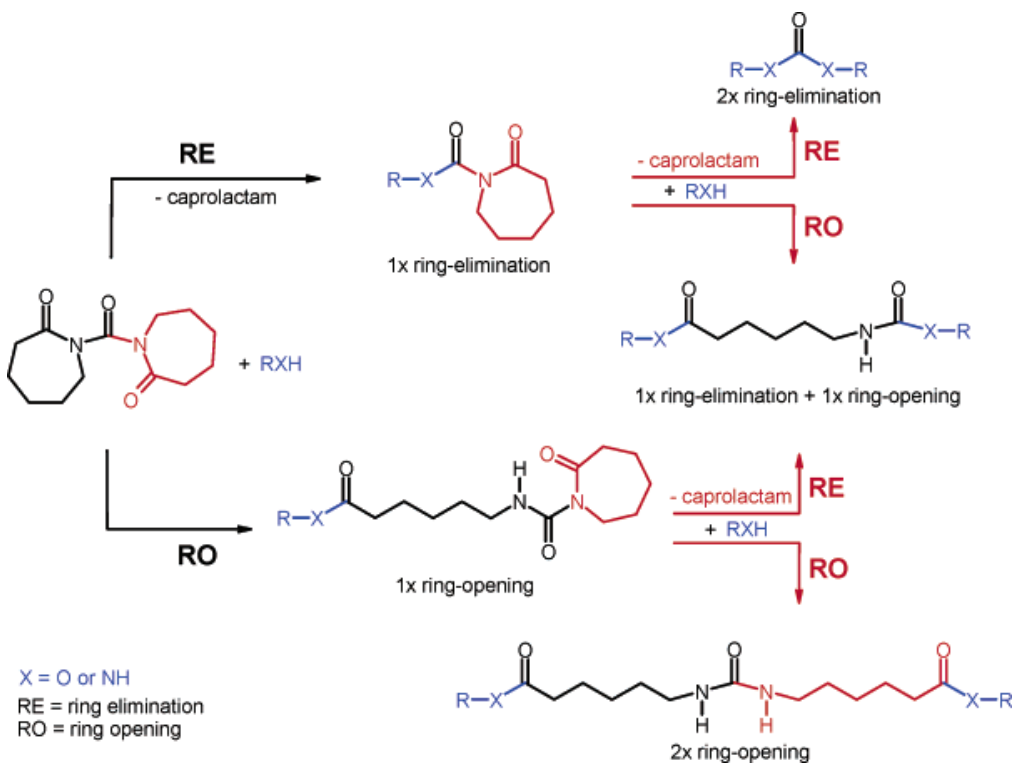

a Pathway RE: Ring elimination mechanism associated with caprolactam formation. Pathway RO. Ring opening reaction of the CBC caprolactam ring.

\section{Scheme 2 CBC Reaction with Amine End Groups of Isopropylenamine-Terminated Oligopropyleneoxides (Jeffamine) According to the Ring Elimination Mechanism}
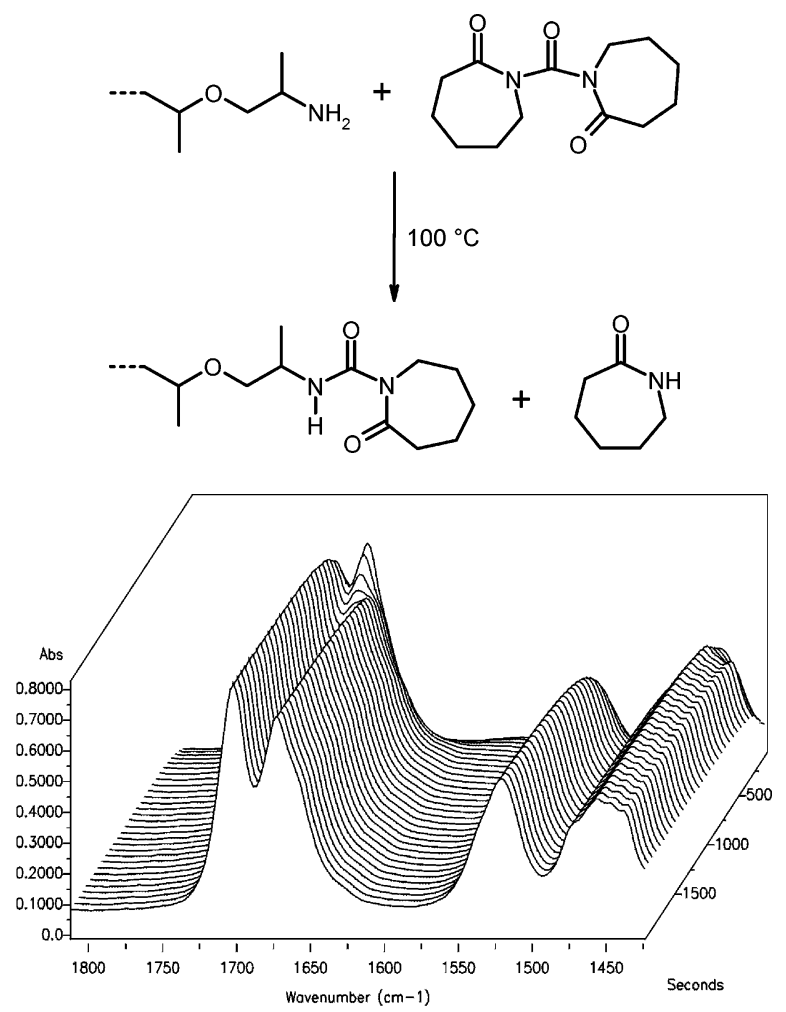

Figure 1. ReactIR spectra of reaction of $\mathrm{CBC}$ with Jeffamine M-600 at $100^{\circ} \mathrm{C}$ (SMA353) in the absence of catalyst. In back: CBC, bands at 1708 and $1684 \mathrm{~cm}^{-1}$. In front: $95 \%$ $N$-carbamoyl caprolactam termninated Jeffamine, bands at 1706,1673 and $1520 \mathrm{~cm}^{-1}$.

and $200{ }^{\circ} \mathrm{C}$ in the absence and in the presence of catalysts such as $\mathrm{Zr}(\mathrm{OR})_{4}, \mathrm{MgBr}_{2}$ and dibutyltindilaurate (DBTDL). The reaction compositions and the product properties are summarized in Tables 2 and 3. An unexpected effect of the catalyst addition was discovered. In the absence of catalyst the reaction of CBC proceeded mainly via ring elimination pathway

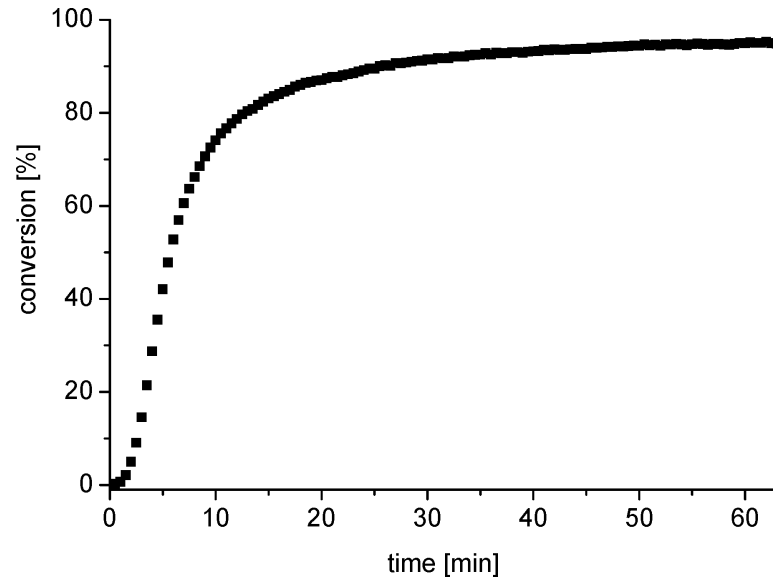

Figure $2 \mathrm{CBC}$ conversion to blocked isocyanates as a function of time. The reaction of CBC with Jeffamine M-600 was carried out at $100^{\circ} \mathrm{C}$ in bulk without catalyst. After 60 $\min , 95 \%$ of the amine end groups of the Jeffamine were transferred into caprolactamblocked isocyanates. The conversion was determined by ReactIR spectroscopy (evaluation of the amide II band at $1520 \mathrm{~cm}^{-1}$, calibration with ${ }^{1} \mathrm{H} N \mathrm{NM}$ spectroscopy).

$\mathrm{RE}$, similar to the reaction pathways established for phosgene and other carbonic acid derivatives such as carbonyldiimidazole and similar to the reaction with amines. In the absence of ring opening, CBC conversion of hydroxy groups gave mainly $N$-carboxylate caprolactam (denoted as $1 x$ ring elimination in Table 2 ) in conjunction with urethane and carbonate, both of which result from subsequent reaction of the $N$-carboxylate caprolactam with hydroxy groups. In sharp contrast, catalyst addition promoted reaction pathway ROinvolving ring opening of one or even two of the CBC caprolactam rings. While the tin catalyst DBTDL was less effective, zirconium alcoholate and Lewis acids such as magnesium bromide gave high conversion and predominant ring opening (cf. Table 2 ). This ring-opening reaction of $\mathrm{CBC}$ with hydroxy-terminated oligomers represents a very attractive new, isocyanate-free route to blocked isocyanates derived from polyols! 
<smiles>COC[C@H](I)OC[C@H](I)N(C)C(=O)N1CCCCCC(Cl)C1</smiles>

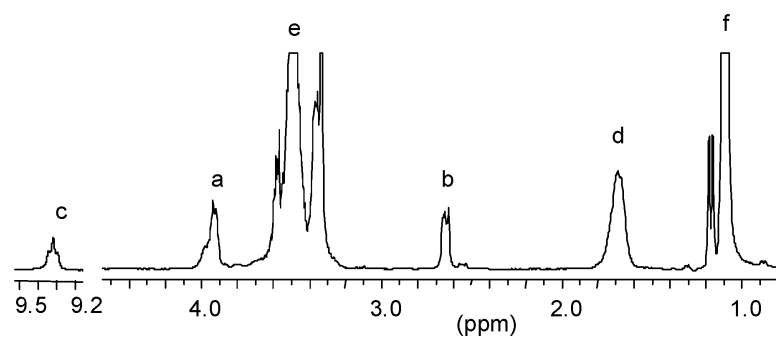

Figure 3. ${ }^{1} \mathrm{H}$ NMR spectrum of the caprolactam-blocked isocyanate derived from $\mathrm{CBC}$ and the isopropyleneamine terminated oligopropyleneoxide (Jeffamine M-600). Reaction conditions: $100^{\circ} \mathrm{C}, 60 \mathrm{~min}$, and conversion $=95 \%$
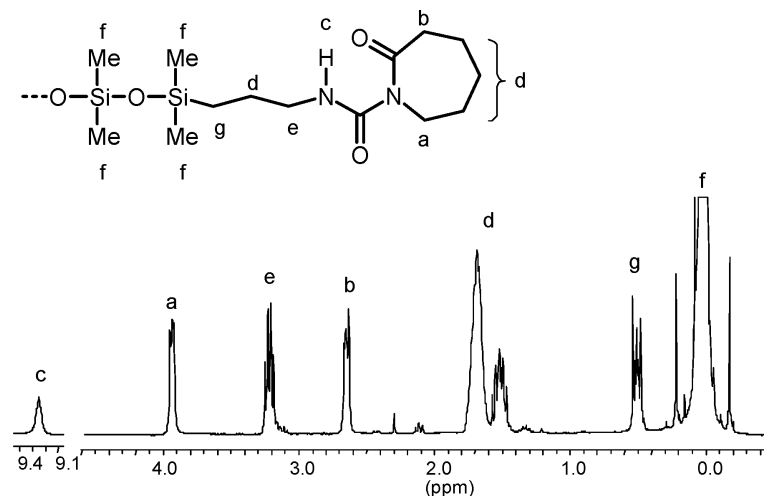

Figure $4{ }^{1} \mathrm{H}$ NMR spectrum of the caprolactam-blocked isocyanate derived from CBC and the bis (propyleneamine)terminated poly (dimethylsiloxane).

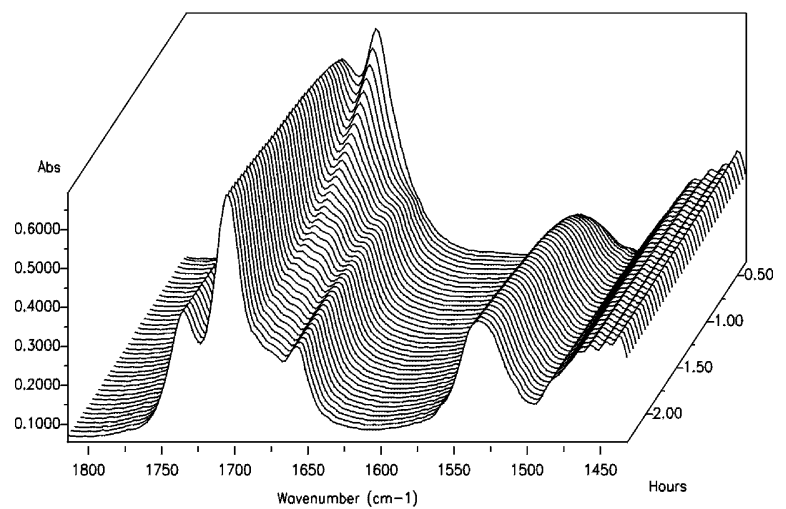

Figure 5. ReactIR spectra of the reaction of CBC with PTHF, catalyzed by $0.75 \mathrm{~mol} \% \mathrm{Zr}(\mathrm{OR})_{4}$ with respect to $\mathrm{CBC}$ at 100 ${ }^{\circ} \mathrm{C}$ (SMA223). In back: CBC, bands at 1706 and $1673 \mathrm{~cm}^{-1}$ In front: product mixture containing $82 \% 1 x$ ring-opened $\mathrm{CBC}$, bands at $1735,1705,1656$ and $1536 \mathrm{~cm}^{-1}$.

The reactions of $\mathrm{CBC}$ with polyols were also monitored by means of ReactIR. Typical ReactIR traces are displayed in Figure 5. The conversion of CBC with hydroxy groups to produce caprolactam-blocked isocyanate end groups was calculated from the area under the amide II band at $1536 \mathrm{~cm}^{-1}$. The calibration of this method was accomplished by correlating the final conversion, as determined by $\mathrm{H} N \mathrm{NM}$ spectroscopy, with the area of this IR band at the end of the reaction. A typical ${ }^{1} \mathrm{H} N M \mathbb{R}$ spectrum of a $\mathrm{CBC}$ reaction with a polyol is displayed in Figure 6.
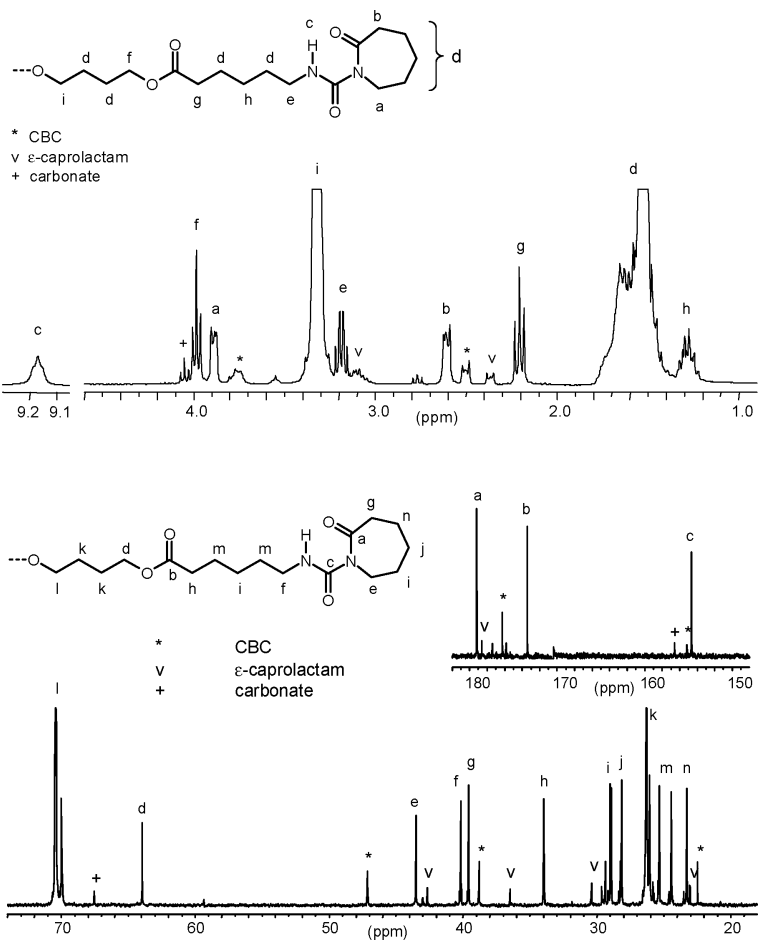

Figure 6 $\mathrm{H}$ and ${ }^{13} \mathrm{CNM}$ spectra of the caprolactam-blocked isocyanate derived from PTHF, synthesized in the presence of $\mathrm{Zr}$-alcoholate $(0.75 \mathrm{~mol} \% \mathrm{Zr}$ with respect to $\mathrm{CBC}$ ) at 100 ${ }^{\circ} \mathrm{C}$ (composition: 82\% caprolactamblocked isocyanate, $6 \%$ carbonate, 12\% $\epsilon$-caprolactam, and 12\% CBC (all with respect to total amount of CBC employed as educt)).

In the absence of catalyst addition the thermal reaction of $\mathrm{CBC}$ with $\mathrm{PTHF}$ at $200^{\circ} \mathrm{C}$ yielded after 75 min 33\% N-carboxylate caprolactam terminated PTHF obtained via elimination of one caprolactam (values are with respect to the employed amount of $\mathrm{CBC}$ ) together with $17 \%$ carbonate via 2 fold caprolactam elimination and $13 \%$ urethane via caprolactam elimination followed by ring opening. In the absence of catalyst no ring opening of the caprolactam rings of $\mathrm{CBC}$ with hydroxy groups occurred! This is strong experimental evidence that thermal reaction of $\mathrm{CBC}$ caprolactam ring proceeds exclusively via the ring elimination pathway (pathway $\mathrm{RE}$ in Scheme 1). According to Table 2 the total conversion of $\mathrm{CBC}$ amounted only to $63 \%$ in that case. For stoichiometric reasons (CBC:hydroxy end group molar ratio of $1 \mathrm{~mol}: 1 \mathrm{~mol} !)$, the total conversion of the CBC cannot reach $100 \%$ when a part of $C B C$ reacts twice with hydroxy groups. The total conversion of the hydroxy end groups was $93 \%$.

When catalyst was added, the reactivity of $\mathrm{CBC}$ increased drastically. In the presence of catalyst the predominant reaction is ring opening according to pathway $\mathrm{RO}$, thus producing the ester-functional $\mathrm{N}$ carbamoyl caprolactam, which is equivalent to a blocked isocyanate end group. The obtained $N$-carbamoyl caprolactam can react with hydroxy groups either via ring elimination or ring opening, thus producing either urethane or urea, respectively. Predominantly urea formation was observed when using sodium or potassium alcoholates at room temperature. Also carbonates were encountered as minor side products, formed via the 2fold ring elimination reactions according to pathway RE.

Scheme 3shows the catalytic reaction of $\mathrm{CBC}$ with $\mathrm{PTHF}$. In this reaction, catalyzed by $\mathrm{Zr}(\mathrm{OR})_{4}$ at $100^{\circ} \mathrm{C}$, 
Scheme 3. Reaction of CBC with PTHF Producing $\mathrm{N}$-Carbamoyl Caprolactam End Groups, Equivalent to Caprolactam-Blocked Isocyanates, via Catalytic Ring Opening Reactions ${ }^{a}$
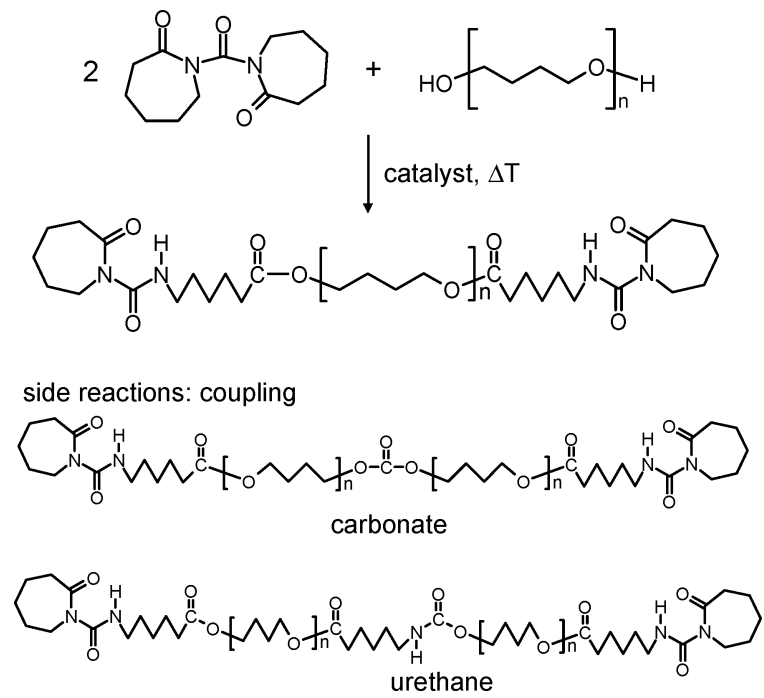

${ }^{a}$ Minor side reactions represent molar mass build up via carbonate chain extension resulting from ring elimination reactions.

$82 \%$ of the $\mathrm{CBC}$ was converted after $120 \mathrm{~min}$ via the $1 x$ ring opening pathway into $N$-carbamoyl caprolactam (caprolactam-blocked isocyanate). This corresponds to a hydroxy conversion of $94 \%$. At $150{ }^{\circ} \mathrm{C}, 85 \%$ (with respect to $\mathrm{CBC}$ ) $N$-carbamoyl caprolactam was formed already after $20 \mathrm{~min}$. This corresponds to a hydroxy end group conversion of 97\%. Carbonate was formed in both reactions to a small extent of only $6 \%$ (with respect to the amount of $\mathrm{CBC}$ employed). Carbonate byproduct formation is tolerated in many applications, since it is associated with the chain extension reaction which does not affect end group functionality. The Lewis acidic catalyst $\mathrm{MgBr}_{2}$ showed almost no activity as catalyst at $100{ }^{\circ} \mathrm{C}$ However, at $150{ }^{\circ} \mathrm{C}$ it yielded $65 \%$ (with respect to $\mathrm{CBC}$ ) of the $N$-carbamoyl caprolactam via the $1 x$ ring-opening reaction (pathway $\mathrm{RO}$ ). This corresponds to $100 \%$ conversion of the hydroxy groups. Here byproducts were found to be $15 \%$ of $N$-carboxylate caprolactam ( $1 x$ ring elimination), $4 \%$ urethane and $6 \%$ carbonate (all with respect to $\mathrm{CBC}$ ). In comparison to $\mathrm{Zr}(\mathrm{OR})_{4}, \mathrm{MgBr}_{2}$ was less active and somewhat less selective. In Figure 7, the addition of $\mathrm{Zr}(\mathrm{OR})_{4}$ and $\mathrm{MgBr}_{2}$ catalysts is compared with respect to the $\mathrm{CBC}$ conversion and formation of the ester-functional $N$-carbamoyl caprolactam. Clearly, the zirconium catalyst is more active than the magnesium catalyst, especially at lower temperatures.

The data of the reactions of $\mathrm{CBC}$ with PEG and with PPO are summarized in Table 2 as well. The CBC reactions with PEG proceeded similarly to reactions of CBC with PTHF. Zr $(\mathrm{OR})_{4}$ catalysis led to $75 \%$ or $85 \%$ of $N$-carbamoyl caprolactam via $1 x$ ring opening at 100 or $15 \mathrm{O}^{\circ} \mathrm{C}$, respectively. $\mathrm{MgBr}_{2}$ catalysis led also to a product distribution quite similar to the $\mathrm{CBCPTHF}$ reaction. Main product was $N$-carbamoyl caprolactam via $1 x$ ring opening, byproducts were urethane, $N$ carboxylate caprolactam via $1 x$ ring elimination, and carbonate. The reactions SMA323 and SMA324listed in Table 2confirm that the $\mathrm{Zr}(\mathrm{OR})_{4}$ catalyst is also more effective than $\mathrm{MgBr}_{2}$ for PPOcontaining the less reactive secondary hydroxy end groups. The reaction of

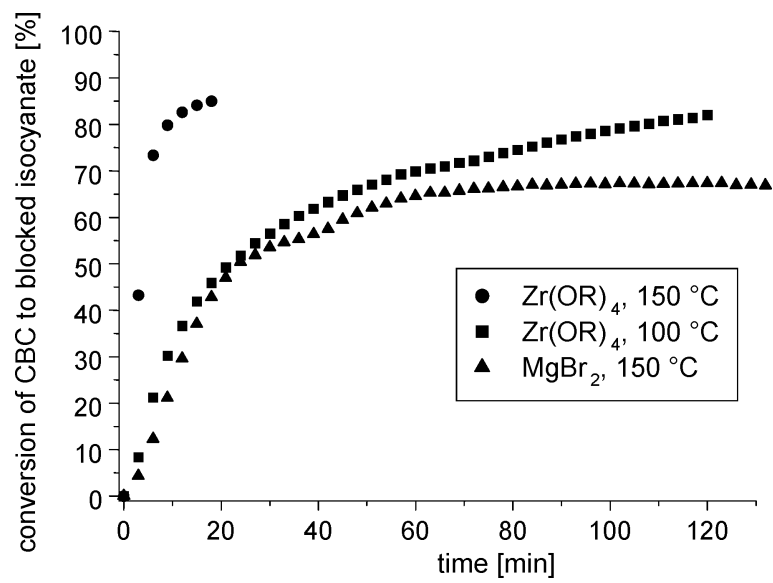

Figure 7. $\mathrm{CBC}$ conversion as a function of time. The reactions of $\mathrm{CBC}$ with $\mathrm{PTHF}$ were catalyzed by $\mathrm{O} .75 \mathrm{~mol} \%$ (with respect to $\mathrm{CBC}) \mathrm{Zr}(\mathrm{OR})_{4}$ at $150^{\circ} \mathrm{C}$ and $100^{\circ} \mathrm{C}$ (SMA225and SMA223) and by $0.75 \mathrm{~mol} \%$ (with respect to CBC) $\mathrm{MgBr}_{2}$ at $15 \mathrm{O}^{\circ} \mathrm{C}$ (SMA238). The conversion was determined by ReactIR spectroscopy (evaluation of the amide II band at $1536 \mathrm{~cm}^{-1}$, calibration with ${ }^{1} \mathrm{H} N \mathrm{NR}$ spectroscopy).

SMA323, catalyzed by $\mathrm{Zr}(\mathrm{OR})_{4}$ at $150^{\circ} \mathrm{C}$, gave complete CBC conversion already after $20 \mathrm{~min}$ and yielded $86 \%$ of the ester-functional $N$-carbamoyl caprolactam via $1 x$ ring opening, whereas SMA234, catalyzed by $\mathrm{MgBr}_{2}$ at the same temperature, needed 70 min for reaching a $\mathrm{CBC}$ conversion of $68 \%$. The reaction mixture obtained in the presence of $\mathrm{MgBr}_{2}$ contained similar amounts of the N-carbamoyl caprolactam and urethane. Again, the addition of $\mathrm{MgBr}_{2}$ appears to be much less effective than $\mathrm{Zr}(\mathrm{OR})_{4}$ with respect to the catalytic formation of the ester-functional $N$-carbamoyl caprolactam via ring opening of exclusively one of the $\mathrm{CBC}$ caprolactam rings.

Characterization of the Oligomers with Caprolactam-Blocked Isocyanate End Groups. Several of the oligotetrahydrofurans with caprolactam-blocked isocyanate end groups, prepared by reacting $\mathrm{CBC}$ with PTHF, were analyzed by means of MALDI-ToF mass spectroscopy.

The MALDI-ToF spectra of the samples produced in the absence and presence of various catalysts are displayed in Figure 8 In the spectrum of SMA2Z3 $\left(\mathrm{PTHF} / 2 \mathrm{CBC} \mathbb{Z r}(\mathrm{OR})_{4} / 100^{\circ} \mathrm{C}\right)$ the three main signals correspond to bis ( $N$-carbamoyl caprolactam)-terminated PTHF, obtained via conversion of both hydroxy end groups according to the $1 x$ ring-opening reaction. No signal of residual PTHF or PTHF containing only one $N$-carbamoyl caprolactam end group were detected. Clearly, as byproduct carbonate-mediated chain extension occurred.

For MALDI-ToF spectrum of SMA238(PTHF RCBC/ $\mathrm{MgBr}_{2} / 15 \mathrm{O}^{\circ} \mathrm{C}$ ) a very similar signal pattern was observed, although three additional weak signals indicate the occurrence of other side reactions which were not identified. In contrast to the spectra of oligomers produced in the presence of catalysts, the spectrum of SMA224 (PTHF 2 CBC tio catalyst $200^{\circ} \mathrm{C}$ ) was very different and confirmed the predominant formation of the bis (N-carboxylate caprolactam)-terminated PTHF, resulting from caprolactam elimination occurring at both chain ends. The MALDI-ToF measurements are in accord with the above-mentioned measurements performed by means of ${ }^{1} \mathrm{HNMR}$ and ReactIR spectroscopy: In the absence of catalysts, CBC mainly reacts with hydroxy end groups via the ring elimination reaction (pathway RE), thus producing $N$-carboxylate 

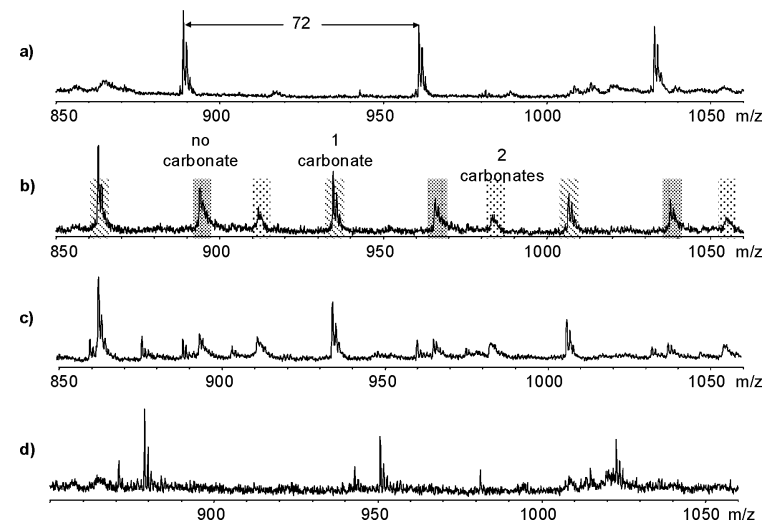

Figure 8 MALDI-ToF mass spectra of (a) PTHF and (b) its reaction products with $\mathrm{CBC}$ from reaction $\mathrm{SMA223}$, catalyzed by $\mathrm{Zr}(\mathrm{OR})_{4}$, and (c) SMA238, catalyzed by $\mathrm{MgBr}_{2}$, and (d) the corresponding reaction product obtained in the absence of catalyst. The signals in parts $\mathrm{b}$ and $\mathrm{c}$ belong to PTHF with two blocked isocyanate end groups (ring-opening reaction) and $\mathrm{Q}, 1$, or 2 carbonate units in the chain ( $2 x$ ring elimination reaction). The signals of part $\mathrm{d}$ belong to bis ( $N$-carboxylate caprolactam)-terminated PTHF ( $1 x$ ring elimination reaction).

caprolactam together with carbonate and urethane via elimination or opening of the other ring. In contrast, the catalyst addition promoted ring opening of mainly one caprolactam ring of CBC, thus producing $N$-carbamoyl caprolactam end groups, which are equivalent to caprolactam-blocked isocyanates. In comparison to the $\mathrm{Zr}(\mathrm{OR})_{4}$ catalyst, the $\mathrm{MgBr}_{2}$ catalyst is somewhat less active and less selective. In the presence of catalyst the CBC-mediated end group conversion proceeds smoothly and is accompanied by formation of small amounts of carbonates.

In addition to MALDI-ToF mass spectrometry also the size exclusion chromatography (SEC) was applied to examine molar masses and molar mass distributions. The polymers obtained in the reactions SMA2Z3 and SMA238 were analyzed by SEC in $\mathrm{CHCl}_{3}$ solution at $30^{\circ} \mathrm{C}$ using linear polystyrene as molar mass standard. The results are listed in Table 3 The $N$-carbamoyl caprolactam terminated PTHF obtained exhibited somewhat higher molar masses with respect to that of PTHF starting material. This is due to the end group formation via CBC reaction and also to chain extension, e.g., via carbonate formation. In fact, molar mass buildup was less pronounced for $N$-carbamoyl caprolactam blocked PTHF prepared in the presence of the $\mathrm{Zr}(\mathrm{OR})_{4}$ catalyst than in the presence of $\mathrm{MgBr}_{2}$ catalyst, due to more molar mass buildup via carbonate chain extension as side reaction.

Samples of dihydroxy-terminated and of the corresponding bis ( $N$-carbamoyl caprolactam)-terminated PTHF were analyzed by means of thermogravimetric analysis (TGA) in order to examine their thermal degradation behavior in view of the deblocking temperatures indicating the decomposition of the $N$-carbamoyl caprolactam into free caprolactam and isocyanate. As a function of isocyanate type and catalysts, the deblocking temperature of conventional caprolactam-blocked isocyanates is known to vary from 160 to $200^{\circ} \mathrm{C} .^{1} \mathrm{At}$ temperatures above $300^{\circ} \mathrm{C}, \mathrm{PTHF}$ depolymerizes, thus yielding $\mathrm{THF}$. The ceiling temperature for the depolymerization of PTHF with active end groups is approximately $80^{\circ} \mathrm{C}$. It is well-known that metal ions such as $\mathrm{Zr}^{4+}$ or $\mathrm{Mg}^{2+}$ can promote chain scission and subsequent depolymerization via an unzipping reaction.

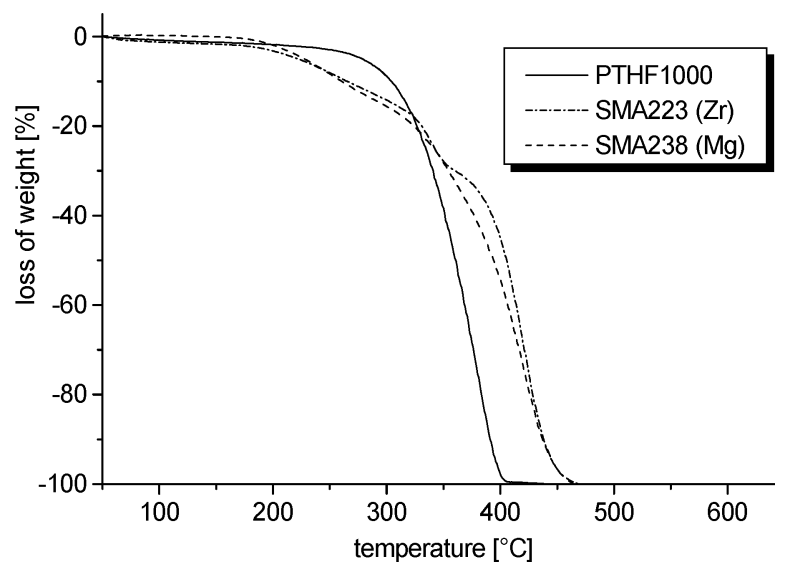

Figure 9. Thermogravimetric analysis of PTHF and the corresponding caprolactamblocked isocyanate, synthesized in the presence of $\mathrm{Zr}$-alcoholate (SMAZ23) and $\mathrm{MgBr}_{2}$ (SMA238) as catalysts.

Figure 9displays the temperature-dependent weight loss of dihydroxy- and bis ( $N$-carbamoyl caprolactam)terminated PTHF. The dihydroxy-terminated PTHF degraded in a single step with an onset degradation temperature of around $270^{\circ} \mathrm{C}$. For the bis ( $N$-carbamoyl caprolactam)-terminated PTHF, prepared via CBCmediated end group conversion of dihydroxy-terminated PTHF in the presence of zirconium and magnesium catalysts, the degradation process exhibited two different steps. Above $180^{\circ} \mathrm{C}$ the weight loss of approximately $20 \%$ is likely to be associated with the thermal deblocking of the end groups, involving formation of caprolactam and isocyanate. The magnesium and zirconium catalyst addition appeared to have little influence on this deblocking temperature. The thermal degradation of the bis (N-carbamoyl caprolactam)-terminated PTHF occurred at a higher temperature of $320^{\circ} \mathrm{C}$ compared with only $270^{\circ} \mathrm{C}$ for the dihydroxy-terminated PTHF. This increase of thermal stability is likely to be associated with isocyanurate ring formation resulting from trimerization of the isocyanate intermediates resulting from the deblocking reaction.

\section{Conclusions}

The stoichiometric end group conversion of amineand hydroxy-terminated oligomers by means of the nontoxic carbonylbiscaprolactam (CBC) represents a very convenient phosgene- and isocyanate-free route to the preparation of a wide range of bis- and poly $(N-$ carbamoyl caprolactam)-terminated oligomers which are equivalent to caprolactam-blocked isocyanate resins. A great variety of oligomers and reactive liquid rubbers with caprolactam-blocked isocyanate end groups are readily available in solvent-free CBC-mediated end group conversion reactions and do not require safety precautions typical for handling toxic isocyanates. The CBC-mediated end group conversion in bulk can be controlled via end group type and catalyst addition. In the absence of catalysts, amine end group react exclusively via ring elimination (pathway $\mathrm{RE}$ ), thus producing N-carbamoyl caprolactam-terminated oligomers which are equivalent to caprolactam-blocked isocyanateterminated oligomers. This reaction proceeds smoothly at elevated temperatures around $100^{\circ} \mathrm{C}$.

In contrast to other derivatives of carbonic acid such as carbonyldiimidazole, CBC offers new opportunities for tailoring reactive oligomers via selective ring-open- 
ing reaction of either exclusively one or both $\mathrm{CBC}$ caprolactam rings. The ring-opening reaction (pathway $\mathrm{RO}$ ) was demonstrated for the CBC-mediated end group conversion of hydroxy-functional oligomers. Only in the presence of catalysts such as alcoholates or Lewis acids, ring opening of the $\mathrm{CBC}$ caprolactam ring occurs, thus producing ester-functional $N$-carbamoyl caprolactams. It would be rather difficult to produce such oligomers via phosgenation because the conventional synthesis would require formation of aminocapronic acid esters of the hydroxy-terminated oligomers followed by phosgenation. The catalytic promotion of ring opening reduces the caprolactam emission during the reaction, thus reducing volatile organic compounds. The formation of chelating complexes with catalysts represents the key to control the reactivity of both carbonyl groups of the CBC caprolactam rings independently. While sodium alcoholates catalyze ring opening of both $\mathrm{CBC}$ caprolactam rings to form ester ureas, the addition of zirconium alcoholate or magnesium halides promote the predominant formation of ester-functional $N$-carbamoyl caprolactam resulting from mainly ring opening of only one $\mathrm{CBC}$ caprolactam ring. As a function of the catalyst choice and reaction temperatures it is possible to reduce the amount of carbonate formed via the ring elimination mechanism. The selective ring opening of the $\mathrm{CBC}$ caprolactam rings is very effective for the coupling reactions without emission of caprolactam. The very versatile $\mathrm{CBC}$ mediated hydroxy and amine group conversion uses stoichiometric amounts of CBC and can be applied to end groups as well as amine and hydroxy groups attached to the main and side chains.

In conclusion, the isocyanate-free routes to caprolactam-blocked isocyanates via the CBC mediated hydroxy and amine group conversions offer new opportunities for polymer diversification and formation of reactive oligomers in applications ranging from coatings, adhesives, and sealants to special isocyanate-free polyurethanes and polyureas useful in biomedical applications. Since CBC is nontoxic, such reactions can be performed in conventional processing equipment at elevated temperatures using polymer melts or polymer solutions, respectively. Since various other functional groups are tolerated, it is possible to prepare a large variety of new functional polymers with tailor-made property profiles.

\section{References and Notes}

(1) Wicks, D. A.; Wicks, Z W. Prog. Org. Coat. 1999, 36,148 172

(2) Wicks, D. A.; Wicks, Z W. Prog. Org. Coat. 2001, 41, 1-83

(3) Meyer, H. R. Kunstst., Plast. 1956, 3 160- 162

(4) Fawcett, F. S.; Tullock, C. W.; Coffman, D. D. J. Am. Chem. Soc. 1962 84, 4275-4285.

(5) Okuda, Y.; Mbri, S. N-N-Carbonylbiscaprolactam. JP42017832 B4, Aug 8 1967.

(6) Nagai, E.; Sumoto, M.; Kanai, H. Polymerization of lactams in the presence of alkali and a cocatalyst. JP44029267 B4, Nov 28, 1969.

(7) Udipi, K.; Stebbins, L. R. Lactam-lactone copolymers. US5200498, Apr 61993

(8) Mateva, R.; Delev, O. Polym. J. 1995, 27, 449-460.

(9) Mateva, R.; Delev, O.; Kaschcieva, E. J. Appl. Polym. Sci. $1995,58,2333-2343$

(10) Mateva, R.; Delev, O.; Rousseva, S. Eur. Polym. J. 1997, 33 $1377-1382$

(11) Miller, R.; Wéhlage, T.; Trieselt, W.; Oftring, A.; Kappes, E.; Oetter, G.; Boeckh, D.; Ettl, R.; Hettche, A. Use of heterocyclic compounds as activators for inorganic peroxides DE 19518039 A 1, Nov, 21, 1996

(12) Loontjens, J. A.; Plum, B. J. M. High- molecular polyamide. US6228980B 1, May 8, 2001

(13) Loontjens, J. A.; Plum, B. J. M. Process for the preparation of an $N$-alkyl or $N$-aryl carbamoyl derivative. W00017169 A 1, May 30, 2000.

(14) Loontjens, J. A. Process for the preparation of a carboxylic acid derivative /NOO140178 A 1, July 7, 2001

(15) Loontjens, J. A.; van Benthem, R. A. T.; Plum, B. J. M; Rietberg, J. Thermosetting composition. EP 1132411A 1, Sept 12,2001

(16) Loontjens, J. A.; Plum, B. J. M Chain extension process. WO0166633 A 1, Sept 13, 2001

(17) Loontjens, J. A.; Plum, B. J. M. Process for preparing a branched polymer. W00166617 A2 Sept 13, 2001.

(18) Molhoek, L. J.; Loontjens, J. A.; Spoolder, B. M. J.; Plum, B. J. M Powder paint binder composition. EP 1130039 A 1 , Sept 5, 2001

(19) Bonnard, H.; Ferrucio, L.; Senet, J.-P.; Le Roy, P.-Y. Process for the preparation of N,N-carbonylbislactams. US2001/ CO44532A 1, Nov 22, 2001

MAOR58861 